Article

\title{
Impact of Innovation City Projects on National Balanced Development in South Korea: Identifying Regional Network and Centrality
}

\author{
Jane Ahn ${ }^{1}$, Ducksu Seo ${ }^{2}$ and Youngsang Kwon ${ }^{1,3, * \mathbb{D}}$ \\ 1 Department of Civil and Environmental Engineering, College of Engineering, Seoul National University, \\ 1 Gwanak-ro, Gwanak-gu, Seoul 08826, Korea; anjane@snu.ac.kr \\ 2 Department of Spatial Environment System Engineering, Handong Global University, 558 Handong-ro, \\ Buk-gu, Pohang, Gyeongbuk 37554, Korea; handonge@handong.edu \\ 3 Smart City Research Center, Advanced Institute of Convergence Technology, Seoul National University, \\ Suwon 16229, Korea \\ * Correspondence: yskwon@snu.ac.kr; Tel.: +82-(28)-808200
}

check for updates

Citation: Ahn, J.; Seo, D.; Kwon, Y. Impact of Innovation City Projects on National Balanced Development in South Korea: Identifying Regional Network and Centrality. ISPRS Int. J. Geo-Inf. 2021, 10, 169. https:// doi.org/10.3390/ijgi10030169

Academic Editor: Wolfgang Kainz

Received: 29 December 2020

Accepted: 11 March 2021

Published: 16 March 2021

Publisher's Note: MDPI stays neutral with regard to jurisdictional claims in published maps and institutional affiliations.

Copyright: (c) 2021 by the authors. Licensee MDPI, Basel, Switzerland. This article is an open access article distributed under the terms and conditions of the Creative Commons Attribution (CC BY) license (https:// creativecommons.org/licenses/by/ $4.0 /)$.

\begin{abstract}
Innovation City projects, aimed at balanced national development in South Korea, have relocated public institutions from the Seoul metropolitan area to provinces, decentralizing population and economic functions, over the past decade. This study measured changes in regional centrality (the central and local location or hierarchy of objects in a network) at the 14 cities where Innovation City projects were constructed. Commuter Origin-Destination data were analyzed using Rstudio. In the case of connectivity centrality, 13 out of 14 regions saw a rise in centrality values; among them, Busan, Daegu, and Ulsan belong to large cities. This suggests that the impact of Innovation City projects on established metropolitan areas may not be very significant. Five of the 14 projects increased the value of eigenvector centrality, while 10 increased the centrality ranking. This means that the absolute traffic volume of Innovation Cities across the country had increased, while the centrality of areas around these cities declined, suggesting that Innovation Cities should pursue co-prosperity with surrounding areas. In this way, Innovation Cities can have a positive impact on surrounding areas, and positive externalities of relocation projects are maximized. However, such development effects are confined to Innovation City areas, negatively influencing balanced regional development.
\end{abstract}

Keywords: Innovation City; regional centrality; social network analysis; South Korea; OD data

\section{Introduction \\ 1.1. Research Background}

Innovation City (IC) projects refer to regional cities that integrate newly relocated institutions as part of the national balanced regional development strategy implemented in 2003. Specifically, this strategy was intended to tackle overcrowding in the metropolitan area surrounding Seoul and imbalanced growth in the rest of the country with the goal of developing 10 ICs by relocating government agency headquarters to 11 existing cities and provinces [1]. Starting with the 2003 announcement of the planned relocation of public institutions to provincial areas for balanced national development, the Innovation City Construction Policy prepared a legal basis for the development in 2004, followed by an announcement of the basic principles and measures for implementation. Next, a foundation for mutual cooperation was established, including collecting opinions from local governments and signing basic agreements between metropolitan and provincial areas, before selecting the city for the project in 2006. In 2006, candidate areas were selected for the development of ICs, and 153 government agencies were moved out of Seoul and its surrounding areas between 2007 and 2019, as scheduled [2]. 
The Korean government promoted the policy to build ICs due to the concentration of excessive population and functions in the metropolitan area, including Seoul. More than half of the total Korean population resides in the metropolitan area, and the concentration of important national functions in the metropolitan area has resulted in relatively underdeveloped provinces [3-5]. President Roh Moo-Hyun promoted a balanced development of the country during his presidential campaign [6]. After he was elected president, several new cities were built with the goal of transferring the functions of the central government to local regions to promote the policy of balanced national development $[7,8]$. The multifunctional administrative city (Sejong city) to which the government's administrative functions were relocated and other cities to which the government's public institutions were relocated are called IC. Cities created under this policy, which began in 2006, are now in the process of being completed. This study aims to investigate whether these innovative cities created for balanced national development helped determine growth in the locational importance of public sector relocation areas [9].

As the IC project has entered its second round, research on associated policies has been actively conducted in various fields, and the need for assessing the effect of IC development on balanced urban development has also risen. Considering that urban spatial structure has been reshaped during and after the IC development process, a comprehensive investigation into transitional spatial structures can be conducted to assess whether relevant policy objectives have been achieved [10-13].

Separately, as IC development prioritizes government policy rather than regional demand and characteristics, it takes less time to complete than general urban development, meaning that there has not been enough time to increase interactions with existing cities and connections among old town districts within the city [14]. In addition, since IC areas are mainly provincial cities lacking infrastructure such as educational institutions, cultural facilities, and medical services, for ICs to interact with their surrounding areas, settlement conditions must be met. Ultimately, a lack of environmental development for settlement in these areas leads to low population growth in the areas surrounding ICs, and migration into newly developed ICs [15]. Therefore, this study analyzes changes in the centrality of ICs as spatial factors, based on traffic flows into these cities and connections to adjacent areas, to determine the impact of IC development and facilitation of interregional connections. Our findings provide policy implications critical for achieving the objectives of IC policies of relieving highly concentrated institutional growth in the metropolitan area surrounding Seoul and strengthening independence in the rest of the country.

\subsection{Research Scope}

Existing studies on changes in urban spatial structure have generally focused on analyzing urban hierarchies [16-22]; nonetheless, since 1990, advanced information technology has enabled the use of network-based methods in research on urban structures, creating various structural networks of nations, organizations, and cities [22,23]. Previous studies on urban layer analysis had limitations in using factor analysis to identify and accurately represent flow patterns by correlation coefficients, rather than actual traffic [24], or because only one node is considered using graph theory [25]. Social network analysis, on the other hand, is a further development of graph theory; using the concept of centrality in urban networks can determine the importance of the location of individual cities [22]. This study aimed to identify changes in the national spatial structure by analyzing changes in the centrality of the national transit network. The current study differs from existing research in that it demonstrates the effectiveness of balanced national development policies.

In this context, many researchers, when studying spatial structure, explored commuting traffic flows as a network indicator representing intercity spatial interactions and consequently identified spatial structures resulting from functional connectivity and interaction mechanisms between regions [26]. Social network analysis is commonly used to examine urban spatial structure based on commuting traffic volume as it enables re- 
searchers to identify the characteristics of structural centrality in regions involved and analyze whether each region plays a key role in the influx of labor force [27].

In this study, we measured centrality of urban areas nationwide using interurban commuting traffic data, using Rstudio, to examine the changes in ICs' urban spatial structure and adjacent areas following a decade of IC development. Commuting traffic data is a type of origin to destination (OD) data that quantifies the traffic volume of commuters from their departure to arrival areas. The data show the average daily traffic for commuting purposes by dividing the annual traffic volume by 365 days. Rstudio transforms this OD data to represent the traffic volume of all regions entering a region. In other words, if the number of regions in OD data is 100, it transforms into $10000(100 \times 100)$ long data. The network is then constructed from these data using the graph package. Based on this, this tool can be used to calculate the centrality of all regions. More importantly, we compared pre- and post-development centrality measures for nationwide regions, which were divided into cities, city districts ("Gu"), and province districts ("Gun"), and interpreted the findings for each region based on the conceptual meanings of centrality.

That is, our research was focused on 10 ICs, where government agency headquarters were relocated, in terms of spatial scope and used nationwide commuting traffic data available at city, "Gu," and "Gun" levels as fundamental data to quantify centrality of an individual region. The nationwide origin-destination traffic volume according to commuting travel purposes (OD data) was extracted from the national transport database and used to examine regional spatial structures. The temporal scope of our analysis includes the year 2005 when specific government agency headquarters started being relocated as part of IC development and the year 2018 when most government agencies were relocated to ICs. We examine 10 ICs except for Sejong city and the cities to where some government agencies were relocated individually. Based on changes in the centrality of the country between 2005 and 2018, IC construction has led to some changes in each region's commuting volume, the local IC location, and their ripple effects on surrounding areas. Thus, we can determine whether IC construction actually realized the decentralization of power in metropolitan area and strengthened self-reliance in non-metropolitan area.

\section{Literature Review}

\subsection{Theoretical Review of Social Network Analysis}

Social network theory identifies network structures in terms of nodes (points) and links (connections) between each pair of nodes described in graphic theory using measures, such as centrality, density, structural holes, and centralization [28-33]. This method is used to elucidate the structural relationship of the network by focusing on the interrelationships between the nodes [13,34-37]. Centrality describes how an important position is occupied by each node within a networked structure [38,39]. It can be measured differently depending on perspective, and different measures of centrality are available, namely, degree, closeness, betweenness, eigenvector, and Bonacich $\beta[28,40]$.

Degree centrality is defined as the number of links connected to nodes. Its degree is positively correlated with the total number of connections linked to a node [26,41]. Closeness centrality is calculated as the reciprocal of the sum of the length of the shortest paths between a node and all the other nodes. This approach can be an effective measure of centrality based on overall relationship within a network as it measures the distance between a node and all the other nodes, regardless of whether they are directly or indirectly connected in the network $[23,38]$. Betweenness centrality measures the number of the shortest paths between two different nodes passing through a given node. Eigenvector centrality uses the adjacent matrix to compute centrality as it represents a network in graphic theory. An eigenvector score corresponding to the eigenvalue of the adjacent matrix is assigned as weight $[42,43]$. This method measures not only the nodes directly and indirectly connected in a network but also the centrality of the nodes to which they are connected. Therefore, the influence of a node is greater when it is connected to highscoring nodes, compared to a node connected to low-scoring nodes [44-46]. As it considers 
centrality of the nodes connected and the amount of flow between two nodes as weights, connection to the nodes with high centrality and high amount of flow from one node to the other nodes lead to a high eigenvector centrality [18]. Finally, Bonacich $\beta$ centrality is a generalized version of eigenvector centrality. If the $\beta$ value is + , its centrality score increases due to the large sum of the centralities of all the nodes in a node's neighborhood. If the $\beta$ value is - , it indicates a dominant-subordinate relationship between regions, meaning that nodes with low centrality are "influenced" by or "dependent" on the nodes with high centrality in the network [18,47-49].

A variety of research has been conducted with respect to change in urban spatial structure and regional centrality using empirical analysis. Many previous studies investigated temporal patterns of change to address spatial changes, while the studies on regional centrality used commuting traffic data between home and workplace due to high frequency [41]. In a study by Lee and Kim [26], regional centralities were compared in terms of the level of connectivity and eigenvector centrality measure using commuter traffic data. Joo and Kim [43] used eigenvector centrality and Lee et al. [49] adopted Bonacich $\beta$ centrality to analyze regional centrality.

This study applied degree and eigenvector centrality measures to determine the effect of centrality in the nationwide commuting traffic network. Since degree centrality focuses on direct activities within the network, its use is appropriate for predicting network flow mobility; focusing on control or efficiency within the network, closeness and betweenness centralities are inadequate [28,40]. Hence, we chose degree centrality to analyze commuting flows between regions. The eigenvector centrality is designed to assist degree centrality as it allows for relative perspectives by capturing the centrality of all the nodes connected to a node in addition to the centrality of the node itself [42]. Thus, it is the most appropriate centrality measure to analyze regional networks in ICs and the surrounding areas comprehensively from a relative perspective.

\subsection{Empirical Studies of Innovation Cities and Public Sector Relocation}

Previous studies on ICs are broadly divided into those that explored the effect of ICs on already existing cities and those that proposed policy implications for boosting IC projects.

One study analyzed the population distribution in IC projects of North Jeolla Province to assess the balanced regional development policy [50], and another study analyzed IC projects and the characteristics of government agencies relocated to assess policy outcomes [51], focusing on changes in population, including population influx, into the regions containing IC. Lee assessed the phenomena observed in the cities being designated as IC projects during the planning stage and resulting economic growth to identify issues involving IC development and suggested measures necessary for further improvement [52]. Choi proposed the need for objective analysis to assist in establishing well-established districts for settlements and self-sufficiency and suggested the direction of the second round of the IC policy [53].

Thus, existing studies on IC projects have identified the effects of newly established IC projects and addressed issues relating to relevant policies to suggest the direction of future development. However, these studies involved respondents in a city and their analysis scope was limited to population, land price, housing satisfaction, and so on. In addition, these studies were conducted not long after the completion of IC development as a project, thus identifying the impact of the project on service satisfaction and economic growth was not possible for them. This study examines how the centrality of the regions redesigned into IC projects has been changed using quantified traffic data before and after IC development and provides valuable implications for the second round of the IC policy based on regional development and benefits resulting from the project.

International examples and studies of the relocation of public institutions with the same context as IC policies can sharpen the focus and policy implications of the current study. Some examples of international relocation of public institutions can be found 
in Britain, Ireland, Japan, Sweden, and France, and studies on the relocation of public institutions have mainly been conducted on the effects of balanced regional development and implications of the relocation policy.

Marshall et al. outlined reasons for the increasing interest in public sector migration in Europe and presented successful aspects of each country's policies and additional studies by comparing UK and Irish migration policies [54]. Jefferson et al. investigated the history and motivational factors of civil service transfer by examining the economic benefits and costs of relocating public institutions in the UK [55]. Bae analyzed the theoretical background of France's relocation policy, overview of the relocation policy, the purpose of the relocation, selection, and allocation of the relocation agency, relocation principle, relocation method, implementation mechanism, and transfer performance [56]. Sjöstedt a discourse theoretical approach that provided a clear ontology of identity and identification process in knowledge-intensive government agencies of Sweden, to study how ideological images of places formed geographical identity locations [57]. Kim et al. analyzed the background of balanced national development policy of Japan, policy goals, results of implementation, and results of the policy, and mentioned the need for a review of balanced national development policy and the promotion of Sejong city, ICs, and Company town in South Korea [58].

These studies identified the ripple effects of each country's relocation policy and various subsequent urban phenomena, and discussed implications by evaluating policy performance, but were mostly limited to introducing theoretical examples. This study is meaningful in that it considers the effect of balanced regional development based on quantitative data analysis using commuter traffic data to gauge local growth following the relocation of public institutions.

\section{Methods}

\subsection{Study Process}

The Korea IC project policy assigns different development periods for each IC, thus it is more appropriate to compare and evaluate the data before and after the construction of an IC, rather than measuring annual changes. All public relocation of IC projects began after 2005, therefore there was no development effect in 2005. Similarly, all public relocations of IC projects were completed between 2013 and 2017, before 2018. Therefore, our analysis was based on pre-construction 2005 and post-construction 2018 to compare and analyze the post-centrality relationship indicating the location importance of the country, and identifying the regional structure before and after the construction.

The analysis process is shown in Figure 1. First, data on the 2005 and 2018 commute OD were collected from the National Transportation Database. Next, we pre-processed the commuter traffic OD data using Rstudio, and measured the centrality using the network analysis package graph. Map visualization was done using ArcGIS. For more visually distinct results, the magnitude of degree centrality was categorized into eight classes, and eigenvector centrality up to seven decimal places was determined with six classes of centrality numerical fields.

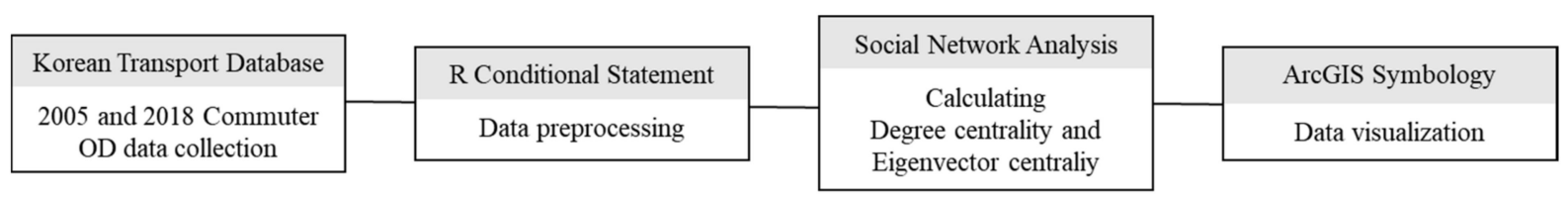

Figure 1. Study process.

This study included 14 cities and districts (Gu and Gun) in 10 ICs except for Sejong city and the cities to where some government agencies moved individually. According to the Innovation Development Promotion Team [59], 112 of the 153 government agency headquarters were relocated to ICs, and the remaining 41 units were individually moved 
to Sejong city and other cities in South Chungcheong Province. The cities to which some government agencies are individually scheduled to move as part of IC development project include Osong and Asan in South Chungcheong Province, Cheongju in North Chungcheong Province, and Daejeon metropolitan city as these cities were additionally designated as Innovation cites in March 2020. These cities were excluded for analysis because the corresponding relocation has not been completed yet, making the comparison of the impact of ICs impossible. Sejong city was also excluded for analysis because its Innovation development has been achieved under a separate urban development plan, which is not comparable with the IC project given its large scale. IC status and location are shown in Table 1 and Figure 2.

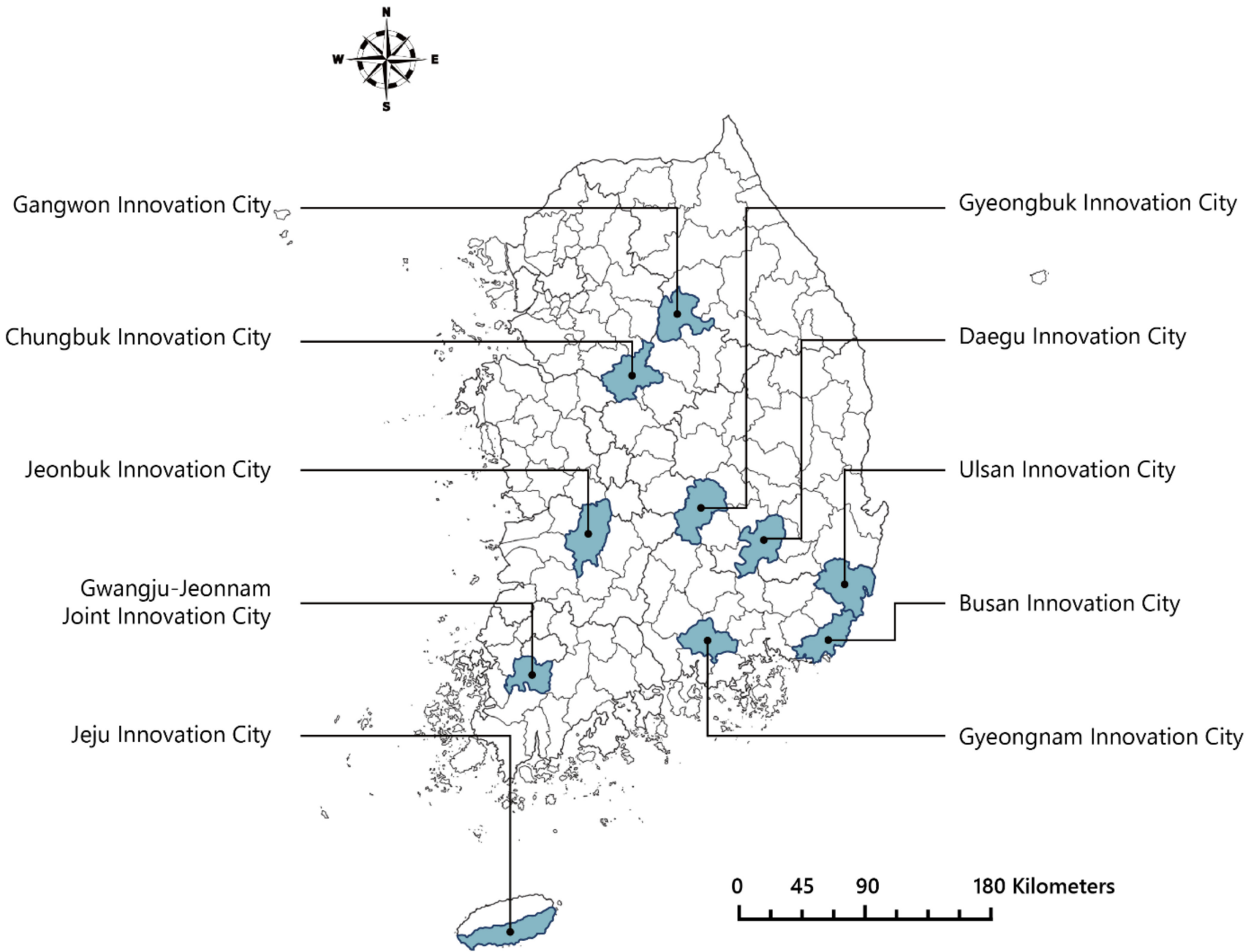

Figure 2. Innovation Cities Districts in South Korea.

Table 1. Status of Innovation City Projects.

\begin{tabular}{|c|c|c|c|c|c|}
\hline Innovation City & Location & $\begin{array}{c}\text { Number of } \\
\text { Institutions Relocated }\end{array}$ & Space $\left(1000 \mathrm{~m}^{2}\right)$ & $\begin{array}{l}\text { Development } \\
\text { Start Date }\end{array}$ & $\begin{array}{c}\text { Development } \\
\text { Completed Date }\end{array}$ \\
\hline \multirow{3}{*}{ Innovation district in Busan } & Youngdo-gu & 4 & 616 & 2007. 04 & 2013. 09 \\
\hline & Nam-gu & 5 & 258 & 2007. 04 & 2014. 09 \\
\hline & Haeundae-gu & 4 & 61 & 2007. 04 & 2013. 06 \\
\hline Innovation district in Daegu & Dong-gu & 10 & 4216 & 2007. 04 & 2015. 12 \\
\hline $\begin{array}{l}\text { Innovation City in South } \\
\text { Jeolla Province }\end{array}$ & Naju & 16 & 7361 & 2007. 03 & 2015. 12 \\
\hline Innovation district in Ulsan & Jung-gu & 9 & 2991 & 2007.04 & 2016. 12 \\
\hline
\end{tabular}


Table 1. Cont.

\begin{tabular}{|c|c|c|c|c|c|}
\hline Innovation City & Location & $\begin{array}{c}\text { Number of } \\
\text { Institutions Relocated }\end{array}$ & Space $\left(1000 \mathrm{~m}^{2}\right)$ & $\begin{array}{l}\text { Development } \\
\text { Start Date }\end{array}$ & $\begin{array}{l}\text { Development } \\
\text { Completed Date }\end{array}$ \\
\hline $\begin{array}{l}\text { Innovation City in } \\
\text { Gangwon Province }\end{array}$ & Wonju & 12 & 3585 & 2007. 03 & 2017. 12 \\
\hline \multirow{2}{*}{$\begin{array}{l}\text { Innovation district in North } \\
\text { Chungcheong Province }\end{array}$} & Jincheon-gun & 6 & 3367 & 2007. 03 & 2016. 12 \\
\hline & Eumseong-gun & 5 & 3532 & 2007. 03 & 2016. 12 \\
\hline \multirow{2}{*}{$\begin{array}{l}\text { Innovation district in North } \\
\text { Jeolla Province }\end{array}$} & Deokjin-gu, Jeonju City & 5 & 3740 & 2007. 04 & 2016. 12 \\
\hline & Wanju-gun & 7 & 6169 & 2007. 04 & 2016. 12 \\
\hline $\begin{array}{l}\text { Innovation City in North } \\
\text { Gyeongsang Province }\end{array}$ & Kimcheon & 12 & 3812 & 2007. 03 & 2015. 12 \\
\hline $\begin{array}{l}\text { Innovation City in South } \\
\text { Gyeongsang Province }\end{array}$ & Jinju & 11 & 4093 & 2007. 03 & 2015. 12 \\
\hline Innovation district in Jeju & Seogwipo & 6 & 1135 & 2007. 04 & 2015. 12 \\
\hline Total & 14 & 112 & & & \\
\hline
\end{tabular}

Source: Current progress in each Innovation City, the Ministry of Land, Infrastructure, \& Transport (2020) [60]. This study included a total of 14 IC projects segmented geographically.

\subsection{Data Collection and Arrangement}

Development of each IC was managed on an individual basis in 10 different cities. However, the whole development process started in 2005 by designating locations for IC and the involved government agencies completed their relocations in 2018. Therefore, nationwide commuting traffic data that correspond to these two years were extracted for analysis: The nationwide origin-destination traffic volume according to commuting travel purposes (OD data) [61] was extracted from the national transport database and used as commuting traffic data.

The database includes nationwide commuting traffic data from 2006 to 2019, and this study used the 2005 and 2018 commuting traffic data released in 2006 and 2019, respectively.

For accurate analysis, we reorganized collected traffic data as follows before calculating centrality. As the relevant administrative districts for 2005 and 2018 were different in terms of name and number of cities and districts ( $\mathrm{Gu}$ and Gun), consolidation was required to make them identical for comparison. According to collected data, a total of 248 zones were available as cities and districts in 2005 and 250 zones in 2018. To elaborate, in 2018, three Gus (Wonmi, Sosa, and Ojeong) were absorbed into the surrounding Guns in Bucheon city, and Yeongi-gun was consolidated into Sejong metropolitan city in South Chungcheong Province. In 2005, the consolidation of Cheongwon-gun in North Chungcheong Province into Cheongju city (Heungdeok-gu and Sangdang-gu) created a new Gu called Seonwon-gu, that occupied certain portions of Heungdeok-gu in Cheongju city and Cheongwon-gun. As part of Sangdang-gu and part of Cheongwon-gun were reorganized into Cheongwon-gu, Cheongju city was divided into Heungdeok-gu, Sangdang-gu, Seowon-gu, and Cheongwon-gu. In 2005, the cities in South Gyeongsang Province (Changwon, Masan, and Jinhae) were reorganized into Uichang-gu, Seongsan-gu, Masanhappo-gu, Masanhoewon-gu, and Jinhae-gu in Changwon city. Accordingly, all the Gus in Bucheon city were categorized into "Bucheon city"; Changwon, Masan, and Jinhae cities were combined into "Changwon" city; and Yeongi-gun in South Chungcheong Province was renamed "Sejong" city for the 2005 data. For the 2018 data, Cheongwon-gu and Seowon-gu in Cheongju city were consolidated into Cheongju city; and Uichang-gu, Seongsan-gu, Masanhappo-gu, Masanhoewon-gu, and Jinhae-gu were consolidated into Changwon city in South Gyeongsang Province. In addition, Dongnam-gu and Seobuk-gu in Cheonan city were consolidated into "Cheonan" city. As a result, the national administrative units totaled 244 zones for 2005 and 2018, respectively. The OD data used in the analysis are shown in Table 2, using inter-regional commuter traffic for 2005 as an example, with the vertical axis representing origin and the horizontal axis for destination. In this example, the point where 1 on the vertical axis intersects with 2 on the horizontal axis, 
indicates the commuting traffic volume from Jongno-gu, Seoul (1), to Jung-gu, Seoul (2). The quantitative value is derived by dividing the total annual traffic by the number of days.

Table 2. Commuter Origin-Destination data sets in 2005.

\begin{tabular}{|c|c|c|c|c|c|c|c|c|}
\hline Region Name & $\begin{array}{c}\text { Origin to } \\
\text { Destination }\end{array}$ & 1 & 2 & 3 & $\ldots$ & 242 & 243 & 244 \\
\hline Jongno-gu, Seoul & 1 & $15,598.44$ & 9860.06 & 1690.46 & & 0 & 0 & 0.57 \\
\hline Jung-gu, Seoul & 2 & 5019.72 & $16,611.05$ & 2487.87 & & 0 & 0 & 0.5 \\
\hline Yongsan-gu, Seoul & 3 & 6488.76 & $13,434.85$ & $20,023.44$ & & 0 & 0 & 16.95 \\
\hline Jeju-do, Jeju-si & 242 & 0 & 0 & 0 & & 0 & 6853.28 & 0 \\
\hline Seogwipo City, Jeju Island & 243 & 0 & 0 & 0 & & 7070.09 & 0 & 0 \\
\hline Sejong City & 244 & 0.92 & 0.84 & 26.12 & & 0 & 0 & 0 \\
\hline \multicolumn{9}{|c|}{ Unit: Volume/day } \\
\hline
\end{tabular}

Source: Korean Transport Database [61], Commuter traffic OD data among the regions.

\subsection{Analytical Models of Centrality}

Regional centrality can be measured by analyzing the traffic flow in the network consisting of the origin and destination. In graph, the places of origin and destination are represented by nodes, and their interactions are linked by a commuting path [19]. We used $\mathrm{R}$ studio with Igraph of $\mathrm{R}$ network packages to compute centrality.

As shown in the following equation, degree centrality is computed as the number of links directly held by each node corresponding to each region in the network. The volume of traffic between regions is represented by links. That is, it refers to the number of nodes attached to a node in the network. The more connections between nodes, the wider the choice and autonomy, which means they have relatively lower dependence on other nodes. As a result, nodes with a high degree of centrality have greater influence on the network [62].

$$
C_{i}=\sum_{j=1}^{n} x_{i j}
$$

$\mathrm{C}_{\mathrm{i}}$ : Degree centrality of node $\mathrm{i}$

$\mathrm{n}$ : The number of nodes

$\mathrm{x}_{\mathrm{ij}}$ : The number of links between nodes $\mathrm{i}$ and $\mathrm{j}$ (traffic volume)

Eigenvector centrality is calculated using the centrality score (i.e., the amount of traffic between regions) and weights (i.e., the traffic volume between nodes) based on the following equation. Eigenvector centrality measures the importance of a node that is proportional to the influence of the nodes that are connected to the node within a network. This means that a node, when connected to nodes with high centrality, has a greater level of influence and vice versa. In terms of eigenvector centrality, nodes connected to a few influential nodes in the network have a larger influence than those connected to more common nodes [62].

$$
C_{i}(\alpha, \beta)=\sum_{j=1}^{n}\left(\alpha+\beta C_{j}\right) x_{i j}
$$

$C_{i}(\alpha, \beta)$ : Eigenvector centrality of node $i$

$\alpha$ : A constant used to compute standardized centrality index

$\beta$ : Level of interactions

$\mathrm{x}_{\mathrm{ij}}$ : The number of links between nodes i and $\mathrm{j}$ (traffic volume) 


\section{Results}

\subsection{Analysis of Commuter Volumes}

This study used a nationwide traffic network and analyzed its characteristics by identifying the volume of commuting traffic across regions and in ICs for 2005 and 2018 and by expressing the changes between the two years as a percentage, prior to centrality calculations. As shown in Figure 3 and Table 3, the volume of commuting traffic increased nationally and in ICs in 2018, compared to 2005. The nationwide commuting traffic volume in 244 cities and districts (Gu and Gun) increased 2.2-fold during the same period. The commuting traffic volume in 14 IC projects showed a greater, 3.3-fold increase during the same period. The volume of commuting traffic directed to IC accounted for $3.2 \%$ and $4.9 \%$ of total traffic volumes in 2005 and 2018, respectively, showing a significant increase. The greater rate of increase in IC traffic compared to the nationwide increase in traffic, indicate a relative increase in IC commuter traffic due to their development.

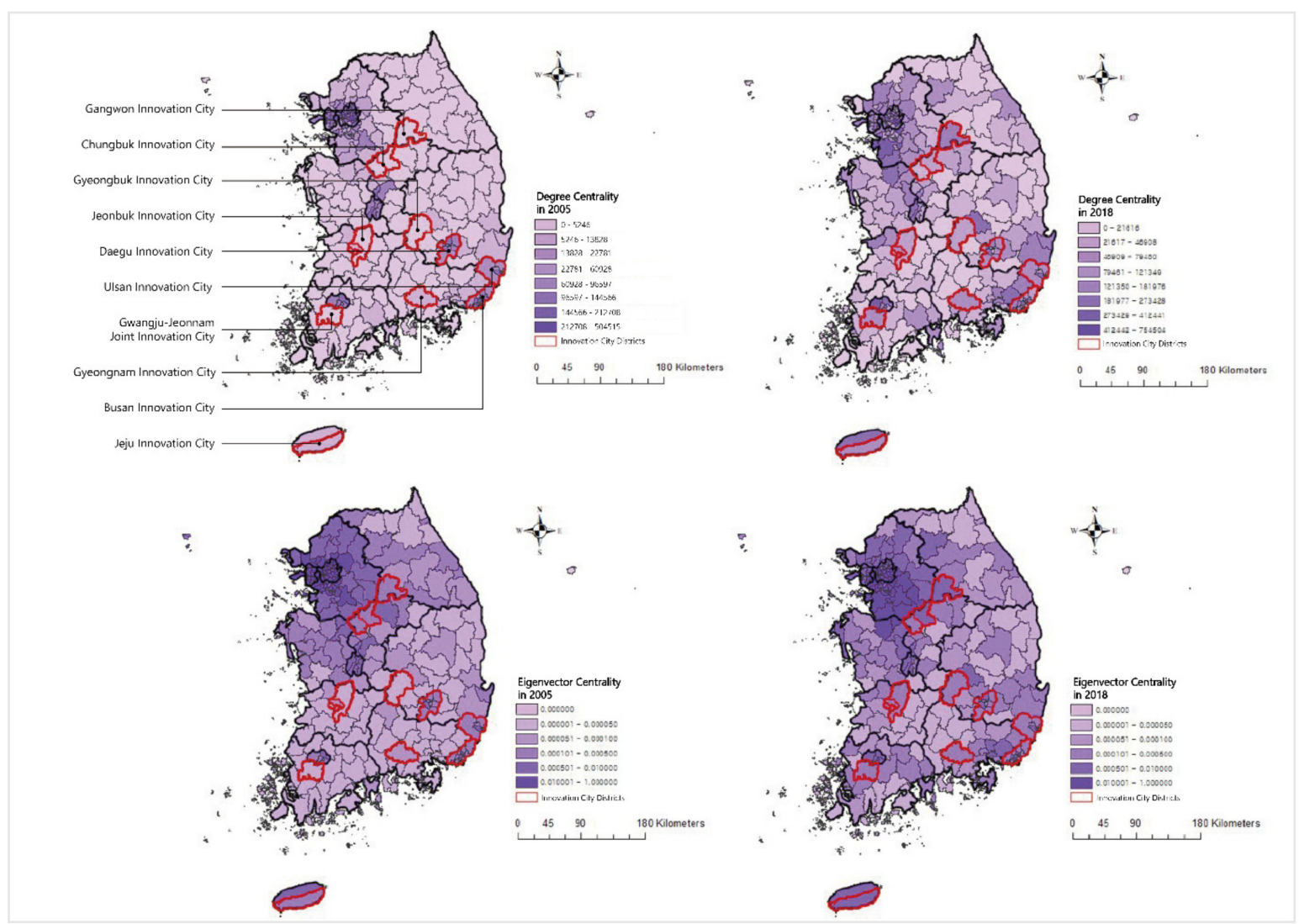

Figure 3. Degree centrality and eigenvector centrality of nationwide cities and districts.

Table 3. Total commuter volumes across regions and in IC cities for 2005 and 2018.

\begin{tabular}{cccc}
\hline Division & Commuting Traffic Volume in 2005 & Commuting Traffic Volume in 2018 & Fold Change \\
\hline Nationwide (244) (A) & $10,116,097$ & $22,463,017$ & 2.22 \\
\hline Innovation City (14) (B) & 331,917 & $1,116,857$ & 3.36 \\
\hline Regions except Innovation City (230) (C) & $9,784,180$ & $21,346,160$ & 2.18 \\
\hline $\begin{array}{c}\text { Ratio of traffic volume in Innovation } \\
\text { City to nationwide traffic volume (B/A) }\end{array}$ & $3.2 \%$ & $4.9 \%$ & - \\
\hline $\begin{array}{c}\text { Ratio of traffic volume in regions except } \\
\text { Innovation City to nationwide traffic } \\
\text { volume (C/A) }\end{array}$ & $96.7 \%$ & $95.0 \%$ & - \\
\hline
\end{tabular}




\subsection{Degree Centrality}

Based on changes in degree centrality of the IC shown in Table 4 and changes in the centrality ranking illustrated in Figure 4, 13 out of 14 IC, except for Youngdo-gu in Busan, exhibited increased centrality and 10 of them moved up the ranks. Nam-gu in Busan, Dong-gu in Daegu, and Jung-gu in Ulsan were found to show increased centrality scores; nonetheless, these districts moved down the rankings, indicating that their increased traffic volumes were not significant to move them up the rankings.

Table 4. Changes in degree centrality of Innovation Cities.

\begin{tabular}{|c|c|c|c|c|c|}
\hline Division & Innovation District & $\begin{array}{c}\text { Degree Centrality in } \\
2005 \text { (A) }\end{array}$ & $\begin{array}{c}\text { Degree Centrality in } \\
2018(B)\end{array}$ & $\begin{array}{c}\text { Changes in Degree } \\
\text { Centrality (B-A) }\end{array}$ & $\begin{array}{c}\text { Growth Rate } \\
\text { [(B-A)/A] }\end{array}$ \\
\hline \multirow{13}{*}{$\begin{array}{l}\text { Centrality } \\
\text { Increased }\end{array}$} & Nam-gu, Busan & 57,155 & 64,500 & 7344 & $12.8 \%$ \\
\hline & Haeundae-gu, Busan & 73,811 & 136,717 & 62,905 & $85.2 \%$ \\
\hline & Dong-gu, Daegu & 81,986 & 103,332 & 21,345 & $26.0 \%$ \\
\hline & Jung-gu, Ulsan & 37,763 & 51,387 & 13,623 & $36.1 \%$ \\
\hline & Wonju in Gwangwon Province & 3164 & 133,907 & 130,742 & $4132.2 \%$ \\
\hline & Jincheon in North Chungcheong Province & 1771 & 40,964 & 39,192 & $2213.0 \%$ \\
\hline & Eumseong in North Chungcheong Province & 1641 & 59,237 & 57,595 & $3509.8 \%$ \\
\hline & Jeonju in North Jeolla Province & 8457 & 87,425 & 78,967 & $933.7 \%$ \\
\hline & Wanju in North Jeolla Province & 2758 & 50,251 & 47,492 & $1722.0 \%$ \\
\hline & Naju in South Jeolla Province & 4499 & 84,104 & 79,604 & $1769.4 \%$ \\
\hline & Gimcheon in North Gyeongsang Province & 3045 & 64,190 & 61,144 & $2008.0 \%$ \\
\hline & Jinju in South Gyeongsang Province & 8079 & 102,851 & 94,771 & $1173.1 \%$ \\
\hline & Seogwipo in Jeju & 6853 & 98,671 & 91,817 & $1339.8 \%$ \\
\hline $\begin{array}{l}\text { Centrality } \\
\text { Decreased }\end{array}$ & Youngdo-gu, Busan & 40,926 & 39,321 & -1605 & $-3.9 \%$ \\
\hline
\end{tabular}

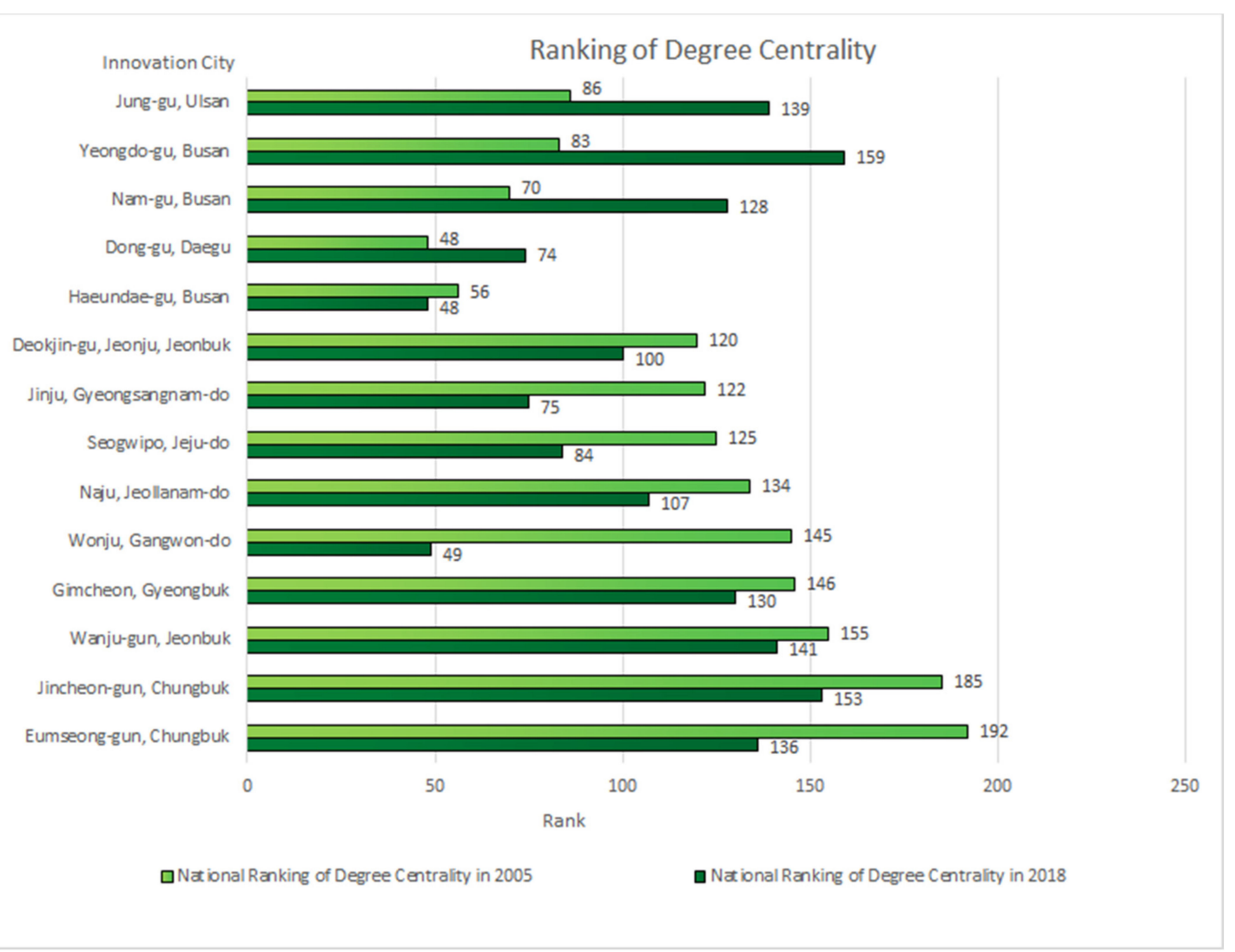

Figure 4. Changes in the degree centrality rankings of Innovation Cities. 
As shown in changes in the centrality rankings (Figure 4), the ranking distributions of the IC did not change significantly between 2005 and 2018. Their rankings spanned over a wide range from 48 th to nearly 230th place during the two years. While the yearly overall distributions exhibited a similar pattern, individual rankings changed at various levels. For example, Youngdo-gu in Busan saw a significantly lower ranking in 2018, compared to 2005. In 2005, this district ranked 83rd at the national level and 3rd among the ICs. However, it ranked 159th at the national level and the second lowest among the IC, showing a significant decrease in its centrality scores. On the contrary, Wonju in Gangwon ranked 145th at the national level in 2005 and 49th in 2018, showing a high increase in its centrality.

\subsection{Eigenvector Centrality}

The changes in eigenvector centrality scores of IC (Table 5) were significantly different from those observed in degree centrality scores. While the overall distributions of the degree centrality rankings displayed a similar pattern in 2005 and 2018 in the regions of IC, the distributions of the eigenvector centrality ranks (Figure 5) showed significant difference during the same period. Among the regions of IC, Wonju in Gangwon Province ranked the highest at 85th place in 2005, followed by other regions that ranked between 100th and 200th places. In 2018, Jinju in South Gyeongsang Province ranked the highest at 5th place at the national level while most of the remaining regions ranked below 100. Thus, it was noted that eigenvector centrality of these IC significantly increased between 2005 and 2018, compared to the national average.

Table 5. Changes in eigenvector centrality of Innovation Cities.

\begin{tabular}{|c|c|c|c|c|c|}
\hline Division & Innovation City & $\begin{array}{c}\text { Eigenvector Centrality } \\
\text { in } 2005 \text { (A) }\end{array}$ & $\begin{array}{l}\text { Eigenvector Centrality } \\
\text { in } 2018 \text { (B) }\end{array}$ & $\begin{array}{l}\text { Changes in Eigenvector } \\
\text { Centrality (B-A) }\end{array}$ & Growth Rate $[(\mathrm{B}-\mathrm{A}) / \mathrm{A}]$ \\
\hline \multirow{5}{*}{$\begin{array}{l}\text { Centrality } \\
\text { Increased }\end{array}$} & Yeongdo-gu, Busan & 0.0000160574 & 0.0036050357 & 0.0035889782 & $22,350.9 \%$ \\
\hline & Nam-gu, Busan & 0.0000314582 & 0.0010921577 & 0.0010606994 & $3371.8 \%$ \\
\hline & Haeundae-gu, Busan & 0.0000378795 & 0.0007512407 & 0.0007133612 & $1883.2 \%$ \\
\hline & $\begin{array}{l}\text { Gimcheon in North } \\
\text { Gyeongsang Province }\end{array}$ & 0.0000385635 & 0.0000732229 & 0.0000346593 & $89.88 \%$ \\
\hline & $\begin{array}{l}\text { Jinju in South } \\
\text { Gyeongsang Province }\end{array}$ & 0.0000715983 & 0.0170358823 & 0.0169642839 & $23,693.7 \%$ \\
\hline \multirow{9}{*}{$\begin{array}{l}\text { Centrality } \\
\text { Decreased }\end{array}$} & Dong-gu, Daegu & 0.0000814766 & 0.0000507924 & -0.0000306841 & $-37.7 \%$ \\
\hline & Jung-gu, Ulsan & 0.0001345104 & 0.0001024963 & -0.0000320140 & $-23.8 \%$ \\
\hline & $\begin{array}{c}\text { Wonju in Gangwon } \\
\text { Province }\end{array}$ & 0.0004676800 & 0.0000292122 & -0.0004384678 & $-93.8 \%$ \\
\hline & $\begin{array}{l}\text { Jincheon in North } \\
\text { Chungcheong Province }\end{array}$ & 0.0001885241 & 0.0000002361 & -0.0001882880 & $-99.87 \%$ \\
\hline & $\begin{array}{l}\text { Eumseong in North } \\
\text { Chungcheong Province }\end{array}$ & 0.0002266961 & 0.0000006282 & -0.0002260678 & $-99.7 \%$ \\
\hline & $\begin{array}{c}\text { Jeonju in North Jeolla } \\
\text { Province }\end{array}$ & 0.0000540505 & 0.0000002376 & -0.0000538129 & $-99.6 \%$ \\
\hline & $\begin{array}{l}\text { Wanju in North Jeolla } \\
\text { Province }\end{array}$ & 0.0000038619 & 0.0000004799 & -0.0000033820 & $-87.6 \%$ \\
\hline & $\begin{array}{l}\text { Naju in South Jeolla } \\
\text { Province }\end{array}$ & 0.0000057187 & 0.0000016672 & -0.0000040515 & $-70.8 \%$ \\
\hline & Seogwipo in Jeju & 0.0001741598 & 0.0000000063 & -0.0001741534 & $-99.996 \%$ \\
\hline
\end{tabular}




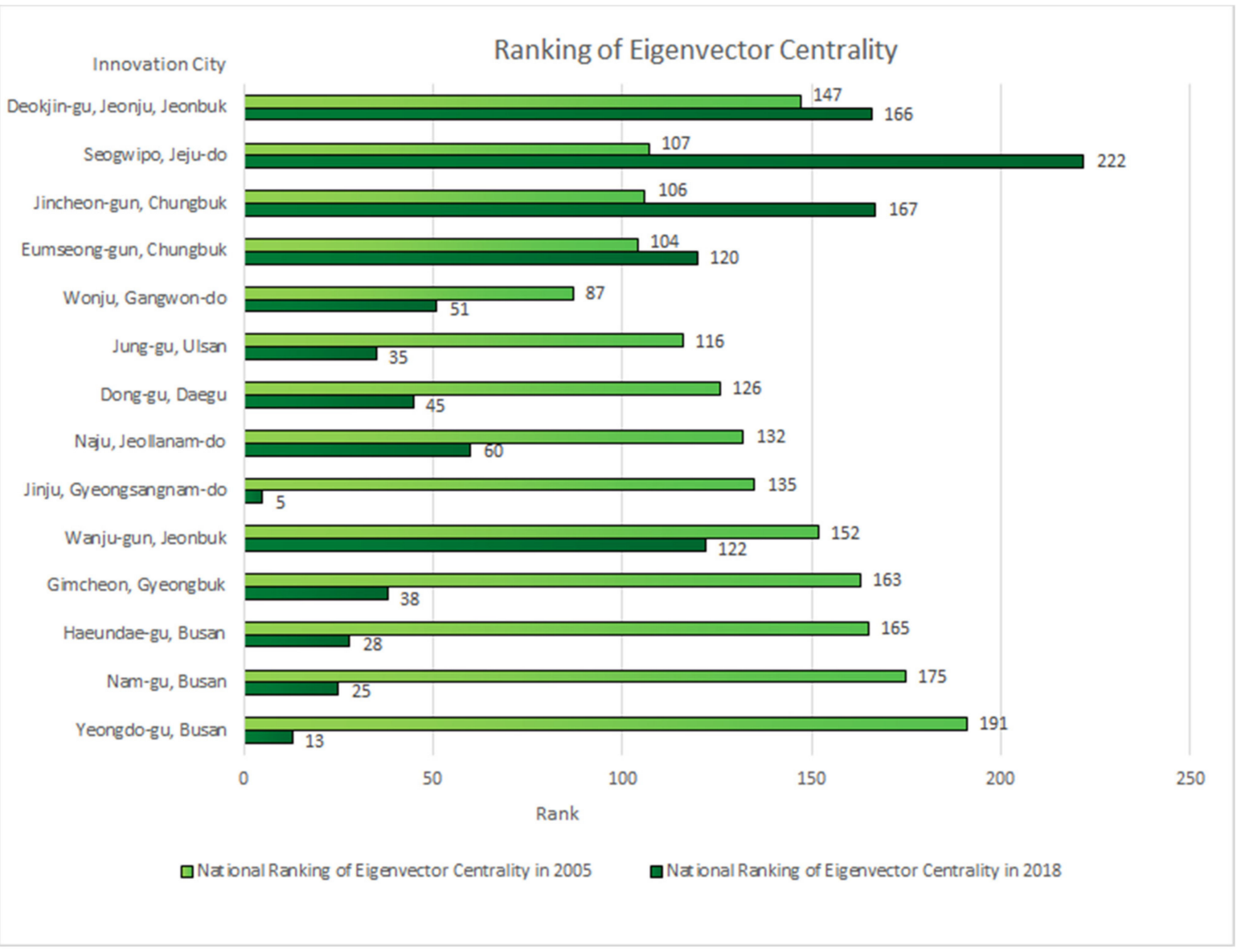

Figure 5. Changes in the eigenvector centrality rankings of Innovation Cities.

As shown in Table 5, only five out of 14 ICs saw increases in their eigenvector centrality between 2005 and 2018, indicating a rather insignificant increase. However, as shown in Figure 5, 10 out of the 14 regions of IC moved up in the corresponding rankings and that is a significant advance, when compared to the national average. Among IC, Dong-gu in Daegu, Jung-gu in Ulsan, Wonju in Gangwon, Wanju-gun, Iksan, and Muju-gun in North Jeolla Province saw their eigenvector centrality scores drop although they achieved a higher ranking at the national level. Thus, changes in eigenvector centrality of IC demonstrated contrasting results when compared to changes in degree centrality. This finding confirms that both centrality measures are different from each other in terms of concept and evaluation perspectives.

\section{Discussion}

\subsection{Regional Development Based on Changes in Degree Centrality}

As shown in Table 4, the individual degree centrality scores of IC increased except for that of Yeongdo-gu in Busan. Yeongdo-gu is the only island among autonomous districts in Korea, making it accessible mainly through four bridges without rail. Therefore, it has a much poorer supply of public transport among the 16 districts in Busan metropolitan city. According to a study on the achievements of Busan IC [63], Dongsam IC, developed in Yeongdo-gu, Busan, has experienced problems with transportation, as well as medical and living facilities. Unlike other IC districts in Busan, Dongsam IC district was separated from the existing central living area, indicating the lowest settlement satisfaction. The characteristics of the Yeongdo-gu area in Busan contributed to the decrease in degree centrality of Yeongdo-gu commuting traffic.

Meanwhile, the centrality of Wonju in Gwangwon Province showed the highest increase among the 14 ICs. While the population is declining in Gangwon as a whole, 
Wonju has seen its population increase steadily over the past five years. Particularly, the population of Jijeong-myeon in Wonju city has increased five times in one year. Increased population movement within and migration flows into Wonju city can be interpreted as its success in establishing a firm foothold as an innovation- and business-friendly city. However, high traffic means there is still a high percentage of people commuting to work from other cities, in line with a follow-up study on IC [64] which found that public institution workers would rather commute by themselves than moving their families from the Seoul metropolitan area to Wonju IC. The fact that Wonju IC in Gangwon-do Province is on the rise in population outflow to the mother town and metropolitan area, and is still affected by the Seoul metropolitan area, enhances the validity of the current results.

As the changes in ranking of degree centrality (Figure 4) and Table 6 show, it was found that the individual absolute amounts of commuting traffic could not increase the importance of centrality in the entire network. Specifically, Nam-gu in Busan, Dong-gu in Daegu, and Jung-gu in Ulsan showed increased commuting traffic volume; nonetheless, these districts moved down in the centrality rankings among ICs. Given that these districts are Innovation districts established within metropolitan cities, these results suggest that the impact of ICs may not be significant at the metropolitan level.

Table 6. Prominent changes in the centrality of Innovation Cities under discussion.

\begin{tabular}{|c|c|c|c|c|c|c|c|}
\hline Division & $\begin{array}{l}\text { Innovation } \\
\text { District }\end{array}$ & $\begin{array}{l}\text { Centrality in } \\
2005\end{array}$ & $\begin{array}{c}\text { Centrality in } \\
2018\end{array}$ & Growth Rate & $\begin{array}{l}\text { Ranking in } \\
2005\end{array}$ & $\begin{array}{l}\text { Ranking in } \\
2018\end{array}$ & $\begin{array}{c}\text { Changes in } \\
\text { Ranking }\end{array}$ \\
\hline \multirow{2}{*}{$\begin{array}{c}\text { Degree } \\
\text { Centrality }\end{array}$} & $\begin{array}{l}\text { Youngdo-gu in } \\
\text { Busan }\end{array}$ & 40,926 & 39,321 & $-3.9 \%$ & 83 & 159 & -76 \\
\hline & $\begin{array}{l}\text { Wonju in } \\
\text { Gwangwon } \\
\text { Province }\end{array}$ & 3164 & 133,907 & $4132.2 \%$ & 145 & 49 & +96 \\
\hline \multirow{5}{*}{$\begin{array}{l}\text { Eigenvector } \\
\text { Centrality }\end{array}$} & Dong-gu, Daegu & 0.0000814766 & 0.0000507924 & $-37.7 \%$ & 126 & 45 & +81 \\
\hline & Jung-gu, Ulsan & 0.0001345104 & 0.0001024963 & $-23.9 \%$ & 116 & 35 & +81 \\
\hline & $\begin{array}{c}\text { Wonju in Gangwon } \\
\text { Province }\end{array}$ & 0.0004676800 & 0.0000292122 & $-93.8 \%$ & 87 & 51 & +36 \\
\hline & $\begin{array}{l}\text { Wanju in North } \\
\text { Jeolla Province }\end{array}$ & 0.0000038619 & 0.0000004799 & $-87.6 \%$ & 152 & 122 & +30 \\
\hline & $\begin{array}{l}\text { Naju in South } \\
\text { Jeolla Province }\end{array}$ & 0.0000057187 & 0.0000016672 & $-70.8 \%$ & 132 & 60 & +72 \\
\hline
\end{tabular}

\subsection{Balanced Regional Development Based on Changes in Eigenvector Centrality}

As shown in Table 5, in the relevant eigenvector centrality rankings nationwide, ICs ranked $87 \mathrm{th}, 104 \mathrm{th}, 106 \mathrm{th}, 107 \mathrm{th}, \ldots$, and 191st in 2005 and 5th, 13th, 25th, 28th, . . , and 222nd in 2018, showing a changed pattern between the two years. The overall increase in the rankings of IC was found at the national level when eigenvector centrality measure was used. This implies that the centrality measure that can consider the centrality of the regions connected to the region with eigenvector centrality is more effective in demonstrating the effects of the IC strategies on regional development.

As shown in Table 6, despite their improved rankings at the national level, the five regions (Dong-gu in Daegu, Jung-gu in Ulsan, Wonju in Gangwon-do, Wanju-gun in North Jeolla Province, and Naju in South Jeolla Province) displayed decreased eigenvector centrality. Given that degree centrality scores of these districts increased, these districts' eigenvector centrality confirms the usefulness of this measure when assessing the effects of the IC strategies. Their decreased eigenvector centrality scores indicate that the traffic flows from several regions with similar centrality; previously, traffic flowed from a limited number of high centrality areas across the country. This means that traffic across the country will be more evenly distributed across regions, compared to the past [62]. Improved rankings during the same period indicate that traffic inflow to areas with low traffic levels in other cities, including the metropolitan area, has decreased, and traffic inflow to ICs and 
nearby mother cities has increased in the nationwide network. This can also be seen in the results of a follow-up study on ICs [65], showing that the population of ICs has a larger inflow from their respective cities than the metropolitan area, thus increasing traffic from metropolitan area to ICs. In this way, the concentration of traffic in the metropolitan area was dispersed and decentralized to local cities, thus realizing the IC policy goal of balanced national development. That is, these districts were influenced by the IC strategies as intended. Thus, IC development has demonstrated that the respective cites/districts with improved eigenvector centrality rankings are able to mitigate the loss of commuting traffic flows into surrounding regions, which can be apparent because of newly established ICs. This finding, coupled with the increased traffic flows into the cities/districts themselves, creates a win-win impact on neighboring regions as well.

The current results supplement limitations identified in previous urban hierarchy analysis studies, by identifying flow patterns using real-world traffic data [24], and considering all regions in the country as nodes [25]. By calculating changes in degree and eigenvector centrality across the country, comparing their differences, and comparing rankings, we could identify the importance of the region of each $\mathrm{IC}$. The purpose of this study was achieved by identifying which IC policies had been realized and which were not, analyzing the impact of implementation, and evaluating IC policies. The results of the degree and eigenvector centralities of this study confirmed that the policy objectives of the development of ICs have been achieved to some extent in terms of overpopulation and functional dispersion in the metropolitan area. Nevertheless, in terms of strengthening local autonomy and balanced development, it was found that the metropolitan area is still affected, or its performance is unclear.

\section{Conclusions}

This study provides the following implications for development of strategies required to achieve sustainable growth in local cities through the newly established ICs.

First, ICs can be further developed in large cities and create social benefits of construction. It was found that all three IC districts with declined rankings at the national level, despite increased commuting traffic flows, are in metropolitan cities. The impact of IC development in Busan, Daegu, and Ulsan metropolitan cities was found to be insignificant. According to previous research [66], ICs are classified as urban expansion, urban connection, city-centered, and city-decentralized, according to their location and effects on surrounding areas. All the Innovation districts in Busan, Daegu, and Ulsan located in large cities are classified as urban expansion; thus, their impact is insignificant to existing cities in terms of population and size [66]. Therefore, Innovation districts located in regions that have become large cities can be further developed to improve their role in providing education, healthcare, and cultural services as part of the effort to increase their self-sufficiency, in addition to the formation of innovation clusters for the second round of the IC project and business-friendly approaches, creating the effects of Innovation district construction in existing cities.

Second, the increases in connectivity and mutually beneficial outcomes are crucial in relation to neighboring regions. In terms of eigenvector centrality, our study showed that the IC development reduced traffic to surrounding areas, and increased traffic from the metropolitan area. This can also be seen from existing studies, where ICs have a larger population inflow from nearby cities than the metropolitan area [65]. Therefore, the traffic volume is the same as the result of greater traffic from the Seoul metropolitan area than the surrounding cities. In the end, it is estimated that it has absorbed some of its functions from the Seoul metropolitan area.

However, it is difficult to say that ICs have sought co-prosperity with surrounding areas by absorbing the population of surrounding cities. Thus, it is necessary to examine whether there is a direct link between the growth of ICs and surrounding areas, and to seek additional paths to development in conjunction with existing cities and surrounding areas, introducing IC Season 2. A policy study after the completion of the Innovative City Season 
1 Project [67] supports the results of the current study, and mentions the need to develop an ecosystem beyond the IC development zone, establish a living zone, and support win-win development projects. In this way, it would likely become necessary to address the decline of established surrounding through the reduction in traffic volume in the surrounding areas, due to the construction of ICs.

One limitation of this study is that it failed to verify other data closely related to traffic volume, such as population inflows and outflows, by analyzing data on commuting volume alone. Future studies could address this limitation through analysis of the centrality results, by dividing areas into metropolitan and other areas and conducting a comparative analysis of changes in centrality between ICs and surrounding areas, thereby yielding more meaningful and prominent results.

Author Contributions: Conceptualization, J.A. and Y.K.; methodology, D.S.; validation, D.S. and Y.K.; formal analysis, J.A. and D.S.; investigation, J.A. and Y.K.; resources, J.A.; data curation, D.S.; writing, J.A. and Y.K.; visualization, J.A. and Y.K.; supervision, D.S. and Y.K.; project administration, Y.K.; funding acquisition, Y.K. All authors have read and agreed to the published version of the manuscript.

Funding: This research was funded by Creative-Pioneering Researchers Program which is funded by Seoul National University and the Basic Science Research Program through the National Research Foundation of Korea funded by the Ministry of Education (2018R1D1A1B07048832).

Institutional Review Board Statement: Ethnical review and approval were waived for this study, as the research was conducted using information available to the general public and not collecting personal identification information.

Informed Consent Statement: Informed consent was obtained from all subjects involved in the study.

Data Availability Statement: The data presented in this study are available on request from the Korean Transport Database. The request for data can be found here: https://www.ktdb.go.kr/www / selectPbldataChargerWebList.do?key=12 (accessed on 25 December 2020).

Acknowledgments: This research was supported by Korea Ministry of Land, Infrastructure, and Transport (MOLIT) as "Innovation Talent Education Program for Smart City." This research was partially supported by the Integrated Research Institute of Construction and Environmental Engineering, the Institute of Engineering Research, and the Institute for Peace and Unification Studies (IPUS) under the project "Laying the Groundwork for Peace and Unification" at Seoul National University. The previous version of this research was presented at the Korean Domestic Conference on 6 November 2020, Online, Korea. The authors wish to express their gratitude for the support.

Conflicts of Interest: The authors declare no conflict of interest. The sponsors had no role in the design, execution, interpretation, or writing of the study.

\section{References}

1. Geum, C.H. The achievements and challenges of relocating public institutions and creating innovative cities. Mon. Public Policy 2017, 139, 20-22.

2. The Ministry of Land, Infrastructure and Transport, Innovation City for Balanced Regional Development. Available online: http:/ / www.molit.go.kr (accessed on 18 July 2020).

3. Bu, X.; Pu, L.; Shen, C.; Xie, X.; Xu, C. Study on the Spatial Restructuring of the Village System at the County Level Oriented toward the Rural Revitalization Strategy: A Case of Jintan District, Jiangsu Province. Land 2020, 9, 478. [CrossRef]

4. Yang, F.; Chi, G.; Wang, G.; Tang, S.; Li, Y.; Ju, C. Untangle the Complex Stakeholder Relationships in Rural Settlement Consolidation in China: A Social Network Approach. Land 2020, 9, 210. [CrossRef]

5. Kwon, Y. Sejong Si (City): Are TOD and TND models effective in planning Korea's new capital? Cities 2015, $42,242-257$. [CrossRef]

6. Kim, M.G.; Park, J.H.; Song, Y.C. A Study on the Impact of the relocation of public institutions to provincial areas on Regional Economic Growth: Administrative City and Innovation City. Natl. Policy Res. 2017, 31, 335-366.

7. Oh, S.W.; Hong, J.H. The effect of infrastructure development policy on local economic employment. Comp. Korean Stud. 2013, 119-144.

8. Yoon, S.D.; Lee, S.W. An Analysis of the Reduction Effect of Congestion Costs by Construction of Administrative City and Innovative City. J. Urban Adm. 2007, 20, 25-50.

9. Jun, M.J. Korea's public sector relocation: Is it a viable option for balanced national development? Reg. Stud. 2007, 41, 65-74. [CrossRef] 
10. Faggio, G. Relocation of public sector workers: Evaluating a place-based policy. J. Urban Econ. 2019, 111, 53-75. [CrossRef]

11. Marshall, J.N. Civil service reorganisation and urban and regional development in Britain. Serv. Ind. J. 1996, 16, 347-367. [CrossRef]

12. Marshall, J.N.; Alderman, N.; Thwaites, A.T. Civil service relocation and the English regions. Reg. Stud. 1991, 25, 499-510. [CrossRef]

13. Williamson, J.G. Regional inequality and the process of national development: A description of the patterns. Econ. Dev. Cult. Chang. 1965, 13, 1-84. [CrossRef]

14. Kang, S.S.; Seo, Y.S. A study on effect of Innovation Cites on Urban Spatial Structure of Existing Cities. Resid. Environ. 2016, 14, 215-232.

15. Kim, Y.S.; Kim, J.J. A Study on the Housing Satisfaction of Residents Working at Public Institutions before Innovation City Development. Resid. Environ. 2016, 14, 73-90.

16. Yang, O.H. A Study on the Urban System by Interaction Analysis. Geogr. Educ. 1979, 9, 203-223.

17. Choi, J.H. A Study on the Urban System in Korea-Through the Spatial Structure Analysis of Finance. Geogr. Educ. J. 1987, 8, 94-123.

18. Lim, S.H. A Study on the Interregional Link and Regional Structural Analysis of National Space-Based on Intercity Bus Flows. Space Soc. 2006, 25, 131-157.

19. Son, S.H. Change of spatial interaction in Seoul Metropolitan Area and the pattern of time and space. J. Korean Geogr. Soc. 2007, 42, 421-433.

20. Choi, J.H.; Park, E.S. Characteristics of urban linkage structure through passenger bus route analysis. Korean J. Urban Geogr. 2013, 16.3, 27-39.

21. Lee, B.J.; Lim, S.H. An Analysis of the Metropolitan City Network using Interaction Index. Korean J. Geogr. Soc. 2014, $20,30-48$.

22. Kim, H.S.; Koo, D.H. A change in the spatial structure of our city network. J. Korean Geogr. Soc. 2019, 54, 621-636.

23. Kim, Y.H. Social Network Theory; Bakyeongsa: Seoul, Korea, 2004.

24. Kim, H.S.; Koo, D.H. A Study on the Reform of Local Administrative System in Korea: Focusing on Regional Linkage. J. Natl. Geogr. Soc. 2011, 45, 249-264.

25. Son, S.H. Changes in Commuting Traffic in Seoul Metropolitan Area and Spatial Separation of Direct-Attention. J. Korean Urban Geogr. 2005, 18, 97-110.

26. Lee, H.Y.; Kim, H.J. Spatial Structure Changes in the Metropolitan Area surrounding Seoul Using Network Analysis, 1980-2000. Natl. Land Plan. 2006, 41, 133-151.

27. Knitter, D.; Nakoinz, O. The Relative Concentration of Interaction-A Proposal for an Integrated Understanding of Centrality and Central Places. Land 2018, 7, 86. [CrossRef]

28. Bonacich, P. Power and Centrality: A Family of Measures. Am. J. Sociol. 1987, 92, 1170-1182. [CrossRef]

29. Borgatti, S.P. Centrality and Network Flow. Soc. Netw. 2005, 27, 55-71. [CrossRef]

30. Carrington, P.J.; John, S.; Stanley, W. Models and Methods in Social Network Analysis; Cambridge University Press: Cambridge, UK, 2005; Volume 28.

31. Friedkin, N.E. Theoretical foundations for centrality measures. Am. J. Sociol. 1991, 96, 1478-1504. [CrossRef]

32. Wasserman, S.; Faust, K. Social Network Analysis: Methods and Applications; Cambridge University Press: Cambridge, UK, 1994; Volume 8 .

33. Nystuen, J.D.; Dacey, M.F. A Graph Theory Interpretation of Nodal Regions. In Papers of the Regional Science Association; Springer: Berlin/Heidelberg, Germany, 1961; pp. 29-42.

34. Alderson, A.S.; Beckfield, J. Power and position in the world city system. Am. J. Sociol. 2004, 109, 811-851. [CrossRef]

35. Boyd, J.P.; Mahutga, M.C.; Smith, D.A. Measuring centrality and power recursively in the world city network: A reply to Neal. Urban Stud. 2013, 50, 1641-1647. [CrossRef]

36. Green, N. Functional polycentricity: A formal definition in terms of social network analysis. Urban Stud. 2007, 44, 2077-2103. [CrossRef]

37. Irwin, M.D.; Hughes, H.L. Centrality and the structure of urban interaction: Measures, concepts, and applications. Soc. Forces 1992, 71, 17-51. [CrossRef]

38. Son, D.W. Social Network Analysis; Kyungmoonsa: Seoul, Korea, 2002.

39. Kim, S.H.; Chang, R.S. The study on the research trend of social network analysis and the its applicability to information science. J. Korean Soc. Inf. Manag. 2010, 27, 71-87.

40. Freeman, L.C. Centrality in Social Networks Conceptual Clarification. Soc. Netw. 1978, 1, 215-239. [CrossRef]

41. Park, K.C.; Jwa, S.H. Analysis of Spatial Structure Changes in the Metropolitan Area Surrounding Seoul using Traffic Volume of Origin-destination Points. Gyeonggi Res. Inst. 2009, 1.

42. Kim, H.C.; Ahn, K.H. The Relationship between Population, Employment, and Social Capital and Centrality of Seoul Metropolitan Areas based on the Connection Network Theory. Natl. Land Plan 2012, 47, 105-122.

43. Joo, M.J.; Kim, S.Y. A Study on Changes in Urban Centrality based on Household-related Traffic. Natl. Territ. Study 2014, 80, 35-48.

44. Cho, J.K.; Heo, W.H. Social Media Mining Using the Eigenvector Centrality in Graphs. Arts Humanit. Soc. Converg. Multimed. J. 2017, 7.4, 183-192. [CrossRef] 
45. Cook, K.S.; Emerson, R.M.; Gillmore, M.R.; Yamagishi, T. The distribution of power in exchange networks: Theory and experimental results. Am. J. Sociol. 1983, 89, 275-305. [CrossRef]

46. Newman, M.E.J. Analysis of weighted networks. Phys. Rev. E 2004, 70, 056131. [CrossRef]

47. Lee, H.Y.; Lee, S.M. The Influence of New Town Development on the Changes of the Migration and Commuting Patterns in the Capital Region. J. Korean Geogr. Soc. 2008, 43, 561-579.

48. Park, S.H.; Lee, W.D.; Cho, C.H. A Study on the Choice of Transportation Means and Regional Characteristics: Based on the Metropolitan Household Survey. J. Korean Geogr. Soc. 2012, 352-357.

49. Lee, J.S.; Seo, Y.C.; Kim, S.R. Measures of Regional Centrality Using Network Analysis. Natl. Territ. Plan 2018, 53, 87-93.

50. Baek, K.H.; Jeon, H.J. A Study on the Change of Population Distribution by the Creation of Innovative New Town-Focused on the case of Jeonbuk Innovation City. Acad. Conf. Korean Assoc. Reg. Dev. 2019, 511-521.

51. Moon, H.J.; Song, J.M. The impact of characteristics of innovative cities and relocation agencies on the migration performance of previous public institutions. Acad. Conf. Korean Assoc. Reg. Dev. 2019, 297-310.

52. Lee, B.S. The Problems and Directions of Innovation City Development Project. Mon. Public Policy 2015, 120, $25-27$.

53. Choi, B.M. How should we proceed with Innovation City Season 2? Urban Inf. 2018, 433, 14-15.

54. Marshall, J.N. Public sector relocation policies in the UK and Ireland. Eur. Plan. Stud. 2007, 15, 645-666. [CrossRef]

55. Jefferson, C.W.; Trainor, M. Public sector relocation and regional development. Urban Stud. 1996, 33, 37-48. [CrossRef]

56. Bae, J.G. France's policy to relocate public institutions to provincial areas. Local Gov. Stud. 2005, 9.4, 171-189.

57. Sjöstedt, L.A. Moving central knowledge to a northern periphery: Exploring logics of public sector job relocation in Sweden. Geogr. Ann. Ser. BHum. Geogr. 2012, 94, 333-350. [CrossRef]

58. Kim, E.K.; Kim, J.G. The limitations and policy implications of Japan's balanced national development policy. Ceo Rep. 2009, 31, $1-25$.

59. Innovative City Development Promotion Team. Available online: https:/ /www.molit.go.kr/ (accessed on 20 July 2020).

60. Ministry of Land, Infrastructure and Transport. Current Status of Project Implementation by Innovative Cities. Available online: https:/ / www.molit.go.kr/ (accessed on 20 July 2020).

61. Korean Transport Database. Available online: https://www.ktdb.go.kr/www/selectPbldataChargerWebList.do?key=12 (accessed on 20 July 2020).

62. NodeXL Korea. Catch up with NodeXL; Paradigmbook: Seoul, Korea, 2015.

63. Bae, S.H.; Kim, J.W.; Jeong, H.J. Basic Plan for the Complex Innovation Center in Busan Innovation District. Busan Dev. Inst. 2019, 179, 80-83.

64. Yoon, J.R.; Kim, H.J.; Bae, J.W. A Study on the Diagnosis and Improvement of Settlement Conditions for Innovation City Residents. Korea Land Hous. Corp. Res. Inst. 2020, 1-175.

65. Kim, T.H.; Min, S.H.; Kim, E.R. Evaluation of 15 years of Innovation City performance and future development strategy. Korea Res. Inst. Hum. Settl. 2020, 775, 1-8.

66. Choi, B.M. A Study on the Classification and Evaluation Index for the Ripple Effects of Innovation Cities to the Surrounding Regions. J. Korean Assoc. Reg. Dev. 2018, 30, 225-241.

67. Shin, H.K. Employment effects of creating and revitalizing Innovation Cities. Korea Labor Inst. 2019, 1-221. 